\title{
Sodium dodecyl sulfate improves the treatment of waste paper with rumen fluid at lower concentration but decreases at higher condition
}

\author{
Shuhei Takizawa ${ }^{1} \cdot$ Yasunori Baba $^{2} \cdot$ Chika Tada $^{1}$ (D) $\cdot$ Yasuhiro Fukuda $^{1} \cdot$ Yutaka Nakai $^{3}$
}

Received: 22 August 2019 / Accepted: 5 December 2019 / Published online: 6 January 2020

(c) The Author(s) 2020

\begin{abstract}
Rumen fluid has been applied to lignocellulosic biomass digest for methane production, and various feed supplements have been shown to improve ruminant digestion of lignocellulosic biomass. Therefore, we investigated the effects of sodium dodecyl sulfate (SDS) on the pretreatment of lignocellulosic biomass with rumen fluid and subsequent methane fermentation. SDS was mixed with rumen fluid at concentrations of $0.1,0.2,0.4$, and $0.8 \mathrm{~g} / \mathrm{L}$. After SDS addition, the waste paper was pretreated with rumen fluid at $37^{\circ} \mathrm{C}$ for $6 \mathrm{~h}$. SDS addition decreased the number of surviving rumen ciliates after pretreatment. SDS addition increased the dissolved chemical oxygen demand during pretreatment; however, SDS addition did not increase the volatile fatty acid concentration. After pretreatment, batch methane fermentation of pretreated waste paper was performed at $35^{\circ} \mathrm{C}$ for 45 days. SDS addition at 0.1 and $0.2 \mathrm{~g} / \mathrm{L}$ shortened the waste paper digestion time and enhanced methane gas production compared to the control. By contrast, SDS addition at 0.4 and $0.8 \mathrm{~g} / \mathrm{L}$ remarkably inhibited methane production from waste paper. These findings suggest that low concentrations of SDS can improve the efficiency of lignocellulosic biomass pretreatment with rumen fluid, and can enhance methane production from waste paper.
\end{abstract}

Keywords Methane fermentation $\cdot$ Pretreatment $\cdot$ Rumen $\cdot$ Sodium dodecyl sulfate $\cdot$ Waste paper

$\begin{array}{ll}\text { Abbreviations } \\ \text { COD } & \text { Chemical oxygen demand } \\ \text { SDS } & \text { Sodium dodecyl sulfate } \\ T_{80} & \text { Technical digestion time } \\ \text { TS } & \text { Total solids } \\ \text { VFA } & \text { Volatile fatty acid } \\ \text { VS } & \text { Volatile solids }\end{array}$

Chika Tada

chika.tada.e1@tohoku.ac.jp

Yutaka Nakai

yutaka-nakai@nafu.ac.jp

1 Laboratory of Sustainable Animal Environment, Graduate School of Agricultural Science, Tohoku University, Yomogida 232-3, Naruko-onsen, Osaki, Miyagi 989-6711, Japan

2 Research Institute for Bioresources and Biotechnology, Ishikawa Prefectural University, Suematsu 1-308, Nonoichi, Ishikawa 921-8836, Japan

3 Department of Agro-Food Science, Faculty of Agro-Food Science, Niigata Agro-Food University, Hiranedai 2416, Tainai, Niigata 959-2702, Japan

\section{Introduction}

Lignocellulosic biomass is an abundant source of renewable energy that can be exploited through anaerobic fermentation and is composed primarily of cellulose, hemicellulose, and lignin. The presence of strong bonds in these polymers forms a firm structure, which resists the hydrolysis of lignocellulosic biomass during anaerobic digestion [1]. Various physical, chemical, and biological pretreatments have been suggested to improve the methane yield by removing lignin, reducing crystallinity, and improving porosity [2-4]. However, these pretreatments have disadvantages, such as the substantial consumption of energy, high cost of reagents, neutralization of wastewater, and production of fermentation inhibiters.

Rumen is an important digestive organ as part of the four stomachs of ruminants. Rumen fluid hosts a complex anaerobic microbial ecosystem consisting of bacteria, archaea, fungi, and protozoa. These microorganisms secrete large amounts of enzymes that can digest lignocellulosic biomass. Thus, the microbial ecosystem can efficiently convert lignocellulosic feed into volatile fatty acids (VFAs) used by the host animal for energy [5-7]. In Japan, 1.1 million 
cattle are slaughtered annually, and a significant amount of rumen fluid is discharged from slaughterhouses. Pretreatment with discharged rumen fluid is a novel method for the efficient methane fermentation of lignocellulosic biomass that minimizes the aforementioned disadvantages. It has been shown to improve biogas production from waste paper, rice straw, and paper sludge, with increases in biogas volume by 1.5-3.2 times compared to production without pretreatment [8-11].

To improve productivity and reduce the environmental effects associated with ruminants, various feed additives have been investigated to improve feed efficiency in ruminants. Quillaja and yucca saponins improve feed use at low doses and modulate ruminal microbial communities in a dose-dependent manner [12]. Supplementation using rain tree pod (Samanea saman) and/or palm oil in cow diets improves the rumen environment. These supplementations increase milk yield, the content of milk protein, and milk fat [13]. Nonionic surfactants, including alkyl polyglucoside, sorbitan trioleate, and Tween-80, improve in vitro fermentation characteristics of cereal straws [14]. Oral administration of sodium dodecyl sulfate (SDS) (at $8 \mathrm{~g} / 100 \mathrm{~kg}$ body weight) as a defaunation reagent decreases digestibility of organic matter but increases ruminal total VFAs and total nitrogen, which indicates improved energy and protein utilization in weaner lambs [15]. However, it is not known whether the application of these feed additives to pretreatment with rumen fluid enhances the digestion of lignocellulosic biomass and methane fermentation. This study investigated the effects of SDS on pretreatment with rumen fluid and on subsequent methane fermentation.

\section{Materials and methods}

\section{Materials}

Rumen fluid was collected from grass-fed lactating Holstein dairy cows through stomach tubes. The dairy cows used in this study were bred in accordance with the regulations of the Institutional Animal Care and Use Committee of Tohoku University (Miyagi, Japan). The collected rumen fluid was immediately filtered $(1 \times 1-\mathrm{mm}$ mesh) to remove coarse fiber and feed residue.

Seed sludge was collected from an anaerobic digester operated at Tohoku University. Before the experiment, $2 \mathrm{~g} / \mathrm{L}$ sodium acetate, $2 \mathrm{~g} / \mathrm{L}$ glucose, $2 \mathrm{~g} / \mathrm{L} \mathrm{NH}_{4} \mathrm{Cl}, 0.016 \mathrm{~g} / \mathrm{L}$ $\mathrm{KH}_{2} \mathrm{PO}_{4}, 0.025 \mathrm{~g} / \mathrm{L} \mathrm{CaCl} \cdot 2 \mathrm{H}_{2} \mathrm{O}, 0.025 \mathrm{~g} / \mathrm{L} \mathrm{MgCl}_{2} \cdot 6 \mathrm{H}_{2} \mathrm{O}$, $0.03 \mathrm{~g} / \mathrm{L} \mathrm{Fe}$-EDTA, $0.005 \mathrm{~g} / \mathrm{L} \mathrm{CoCl}_{2} \cdot 6 \mathrm{H}_{2} \mathrm{O}, 0.005 \mathrm{~g} / \mathrm{L}$ $\mathrm{NiCl}_{2} \cdot 6 \mathrm{H}_{2} \mathrm{O}, 0.005 \mathrm{~g} / \mathrm{L} \mathrm{MnCl}_{2} \cdot 4 \mathrm{H}_{2} \mathrm{O}$, and $0.1 \mathrm{~g} / \mathrm{L}$ yeast extract were added to the seed sludge for acclimation. After biogas production from the seed sludge was stopped, the seed sludge was collected for use in the experiment.
A piece of printed black waste copy paper $(3.0 \mathrm{~cm}$ length $\times 2.0 \mathrm{~cm}$ width) was used as the substrate for pretreatment. The chemical characteristics of the rumen fluid, seed sludge, and waste paper are presented in Table 1.

\section{SDS addition and pretreatment of wastepaper with rumen fluid}

Pretreatment of paper sludge was performed in a $300-\mathrm{mL}$ reactor (working volume: $180 \mathrm{~mL}$ ) equipped with a screw cap. SDS was mixed with $180 \mathrm{~mL}$ of rumen fluid at concentrations of 0.0 (control), $0.1,0.2,0.4$, or $0.8 \mathrm{~g} / \mathrm{L}$-rumen fluid. Then, $5.4 \mathrm{~g}$ of waste paper was added to all reactors $(3.0 \%$ w/v). The mixtures were purged with nitrogen gas to sustain anaerobic conditions and pretreatment was performed at $37{ }^{\circ} \mathrm{C}$ on a rotary shaker at $170 \mathrm{rpm}$ for $6 \mathrm{~h}$. Pretreatment of waste paper with rumen fluid was conducted in triplicate. One of the samples was frozen at $-20{ }^{\circ} \mathrm{C}$ to measure the degradability of waste paper. The other two samples were used for subsequent methane fermentation.

\section{Anaerobic digestion}

Batch methane fermentation was performed in a $600-\mathrm{mL}$ reactor with a working volume of $500 \mathrm{~mL}$. Pretreated waste paper and rumen fluid were mixed with $300 \mathrm{~mL}$ of seed sludge. Then, the mixture was purged with nitrogen gas to remove oxygen and incubated at $35^{\circ} \mathrm{C}$ for 45 days. Batch methane fermentation was conducted in duplicate.

\section{Chemical measurements}

Gas concentrations (methane and carbon dioxide), dissolved chemical oxygen demand (COD), and VFA concentrations were determined as described previously [11]. Briefly, the concentrations of methane and carbon dioxide were measured using gas chromatography (GC-8A;

Table 1 Chemical characterization of materials used in this study

\begin{tabular}{llr}
\hline Material & Parameter & Value \\
\hline Wastepaper & Total COD $(\mathrm{g} / \mathrm{kg})$ & 1046.7 \\
& TS $(\%)$ & 92.2 \\
Rumen fluid & VS $(\% \mathrm{TS})$ & 95.0 \\
& Total COD $(\mathrm{g} / \mathrm{L})$ & 14.3 \\
& Dissolved COD $(\mathrm{g} / \mathrm{L})$ & 8.6 \\
& TS $(\mathrm{g} / \mathrm{L})$ & 6.2 \\
Seed sludge & VS $(\% \mathrm{TS})$ & 68.6 \\
& Total COD $(\mathrm{g} / \mathrm{L})$ & 11.3 \\
& Dissolved COD $(\mathrm{g} / \mathrm{L})$ & 0.4 \\
& TS $(\%)$ & 1.5 \\
& VS $(\% \mathrm{TS})$ & 72.2 \\
\hline
\end{tabular}


Shimadzu, Japan). The dissolved COD was determined using a colorimetric method with Digestion Solution for COD $0-1500 \mathrm{mg} / \mathrm{L}$ vials (Hach, USA). The VFA concentrations were measured using high-performance liquid chromatography (Jasco, Japan). The total solids (TS) and the volatile solids (VS) contents were determined using the methods described by the APHA [16]. The $\mathrm{pH}$ was measured using a pH meter (LAQUAtwin-pH-22B, HORIBA, Japan).

The methane yield was calculated as Eq. (1):

Methane yield (\%) $=\frac{V_{\text {Pretreatment }}+V_{\text {Methanogenic process }}}{T_{\text {waste paper }}+T_{\text {rumen fluid }}+T_{\mathrm{SDS}}} \times 100$,

where $V_{\text {pretreatment }}$ and $V_{\text {Methanogenic }}$ process are the final volume $(\mathrm{mL})$ of methane production after pretreatment and anaerobic digestion processes, respectively. $T_{\text {waste paper, }}$, $T_{\text {rumen fluid }}$, and $T_{\mathrm{SDS}}$ are the theoretical methane production $(\mathrm{mL})$ from waste paper, rumen fluid, and SDS, respectively. The theoretical methane production was calculated based on $350 \mathrm{~mL}$ methane per $1 \mathrm{~g}$ of COD included in materials.

\section{Evaluation of cell viability}

Rumen ciliate viability after treatment was determined via cell counting using the trypan blue-formalin-saline solution method [17]. In this method, both micro- and macronuclei of living rumen ciliates are stained light blue, and other parts of the bodies are either not stained or stained very light blue. By contrast, dead cells are stained dark blue. The total direct count of viable ciliate was based on the use of a Burker-Turk type cell counting plate (WATSON BIO LAB, Japan) and an optical microscope.

\section{Results}

\section{Rumen ciliate viability after pretreatment}

Figure 1 presents the rumen ciliate viability before and after pretreatment. Before pretreatment, the control $(0.0 \mathrm{~g} / \mathrm{L}$ SDS $)$ had a live ciliate concentration of $18.8 \times 10^{4}$ cells $/ \mathrm{mL}$. By contrast, ciliate viability decreased with SDS addition, and the rate of dead cells was 33.3, 44.0, 68.0, and $93.3 \%$ at SDS concentrations of $0.1,0.2,0.4$, and $0.8 \mathrm{~g} / \mathrm{L}$, respectively, compared to the control. After $6 \mathrm{~h}$ of pretreatment, $18.7 \%$ of rumen ciliates survived in the control compared to the control before treatment. By contrast, $9.3,12.0,9.3$, and $0.0 \%$ of cells survived in rumen fluid mixed with SDS at $0.1,0.2,0.4$, and $0.8 \mathrm{~g} / \mathrm{L}$ compared to those before the pretreatment.

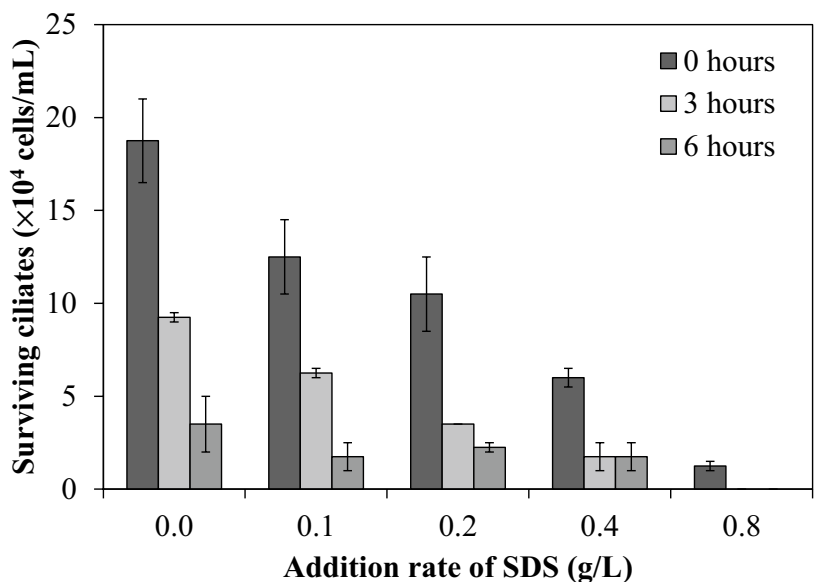

Fig. 1 Number of surviving ciliates during the pretreatment with rumen fluid at various concentrations of SDS
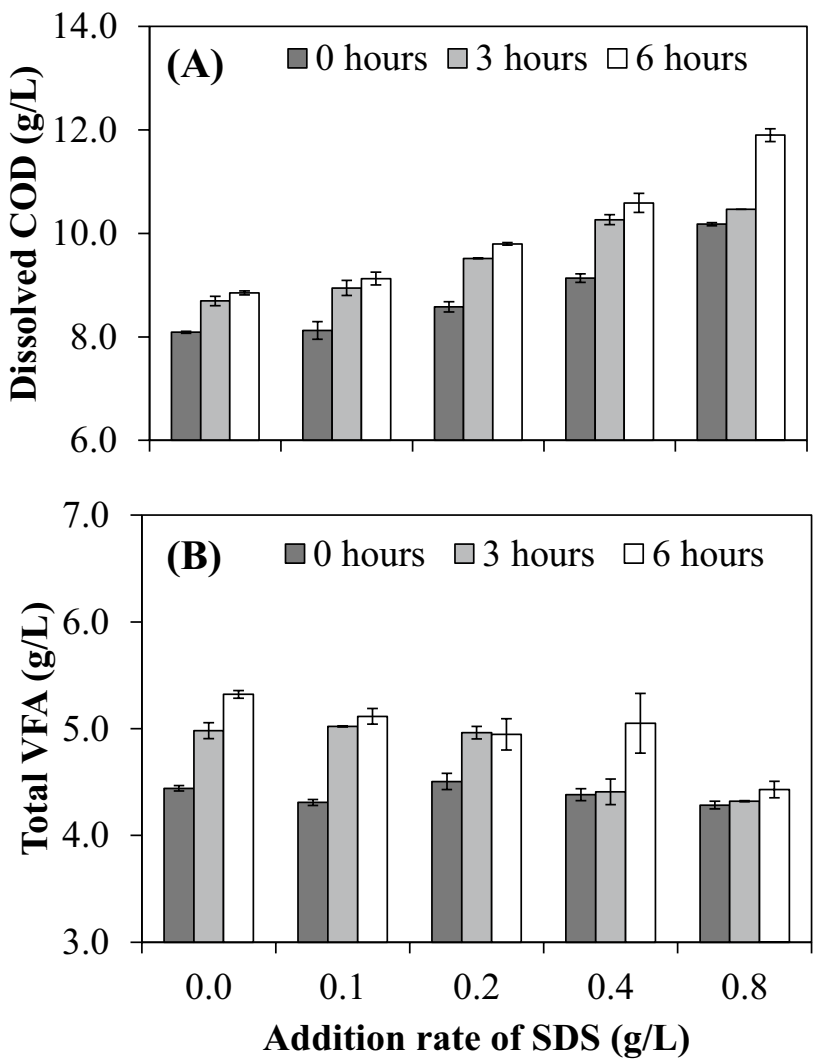

Fig. 2 a Dissolved COD and $\mathbf{b}$ total VFA concentration during the pretreatment of waste paper with rumen fluid at various concentrations of SDS

\section{Solubilization of waste paper during pretreatment}

Waste paper was pretreated using rumen fluid + SDS at different concentrations $(0.0-0.8 \mathrm{~g} / \mathrm{L})$. Figure 2 presents the dissolved COD and total VFA concentrations during 
pretreatment. The dissolved COD concentrations after pretreatment with rumen fluid + SDS were substantially higher than that of the control throughout the pretreatment (Fig. 2a). After $6 \mathrm{~h}$, the dissolved COD content showed increases of $0.8,1.0,1.2,1.5$, and $1.7 \mathrm{~g} / \mathrm{L}$ at SDS concentrations of 0.0 , $0.1,0.2,0.4$, and $0.8 \mathrm{~g} / \mathrm{L}$, respectively. By contrast, SDS addition did not enhance VFA production throughout pretreatment (Fig. 2b), and the addition of $0.8 \mathrm{~g} / \mathrm{L}$ SDS markedly inhibited VFA production during pretreatment. At all SDS concentrations $(0.0,0.1,0.2,0.4$, and $0.8 \mathrm{~g} / \mathrm{L})$, acetic acid and propionic acid were the dominant VFAs. In addition, at $0.4 \mathrm{~g} / \mathrm{L}$ SDS, lactic acid was detected at concentrations comparable to propionic acid (data not shown).

Figure 3 shows the cumulative methane and carbon dioxide production during pretreatment. After $6 \mathrm{~h}$, SDS addition at $0.2,0.4$, and $0.8 \mathrm{~g} / \mathrm{L}$ resulted in decreased methane production by $43.1,95.9$, and $100.0 \%$, respectively (Fig. 3a). By contrast, SDS addition at 0.1 and $0.2 \mathrm{~g} / \mathrm{L}$ increased carbon dioxide production by 72.1 and $37.5 \%$, respectively (Fig. 3b).
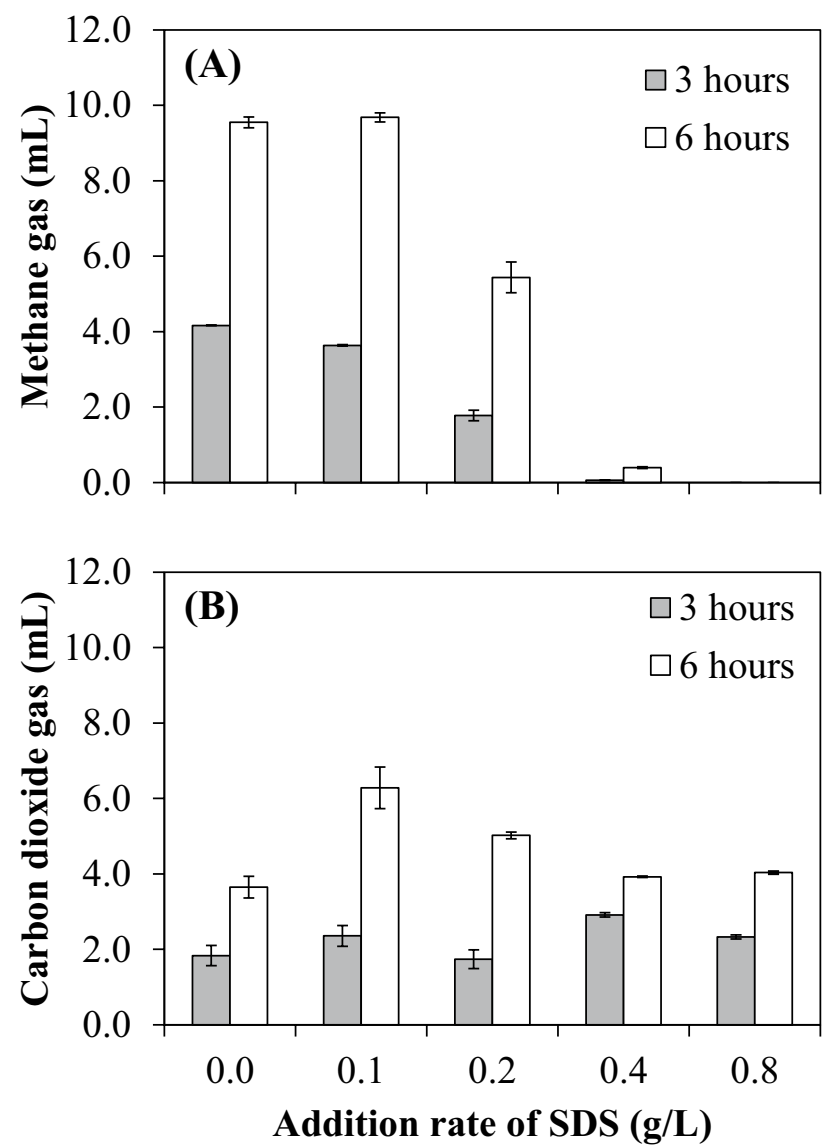

Fig. 3 a Methane gas and $\mathbf{b}$ carbon dioxide gas production during the pretreatment of waste paper with rumen fluid at various concentrations of SDS

\section{Degradation of waste paper}

The TS and VS degradation rates of waste paper during pretreatment and methane fermentation are presented in Table 2. During pretreatment, SDS addition did not remarkably alter the degradability of TS and VS. During methane fermentation, no remarkable differences in TS degradability were observed among the treatments. However, SDS addition at 0.4 and $0.8 \mathrm{~g} / \mathrm{L}$ resulted in decreased VS degradability by 3.2 and $8.5 \%$, respectively.

\section{VFA production during methane fermentation}

Batch methane fermentation of pretreated waste paper was performed at $35{ }^{\circ} \mathrm{C}$ for 45 days. The VFA concentrations during methane fermentation are shown in Fig. 4. Acetic acid, propionic acid, and iso-valeric acid were the dominant VFAs. During the first stage (days 0-4), the VFAs in the batches that underwent pretreatment with $0.0,0.1$, and $0.2 \mathrm{~g} / \mathrm{L}$ SDS increased by $2.8,2.9$, and $1.5 \mathrm{~g} / \mathrm{L}$, respectively, above which the VFA concentrations decreased (Fig. 4). In batches that underwent pretreatment with SDS concentrations of 0.1 and $0.2 \mathrm{~g} / \mathrm{L}$, the acetic acid was completely degraded by day 16 , and propionic acid was degraded by day 40. By contrast, acetic acid and propionic acid accumulated in batches that had been pretreated with SDS concentrations of 0.4 and $0.8 \mathrm{~g} / \mathrm{L}$, and the high concentrations of these VFAs were maintained. Therefore, the $\mathrm{pH}$ of these treatment groups decreased below 6.0.

\section{Methane production from waste paper}

Figure 5 presents the amount of methane produced during methane fermentation. SDS addition at 0.4 and $0.8 \mathrm{~g} / \mathrm{L}$ resulted in a longer lag phase compared with the control. In total, $1700.4,1862.3,1892.3,383.2$, and $346.1 \mathrm{~mL}$ of methane was produced after 45 days when using waste paper pretreated with SDS concentrations of 0.0, 0.1, 0.2, 0.4, and $0.8 \mathrm{~g} / \mathrm{L}$, respectively. Thus, pretreatment with SDS concentrations of 0.1 and $0.2 \mathrm{~g} / \mathrm{L}$ increased methane production by 9.5 and $11.3 \%$, respectively, while pretreatment with SDS

Table 2 Effect of SDS addition on the degradability of waste paper pretreated after pretreatment and methane fermentation

\begin{tabular}{llllll}
\hline & \multicolumn{2}{l}{ Pretreatment } & & \multicolumn{2}{c}{ Methane fermentation } \\
\cline { 2 - 3 } & TS $(\%)$ & VS $(\%)$ & & TS $(\%)$ & VS $(\%)$ \\
\hline Control & 9.0 & 17.7 & & 68.6 & 74.1 \\
SDS 0.1 g/L & 8.5 & 15.5 & & 69.5 & 74.8 \\
SDS 0.2 g/L & 7.1 & 17.8 & & 70.2 & 76.6 \\
SDS 0.4 g/L & 6.9 & 18.6 & & 69.7 & 71.7 \\
SDS 0.8 g/L & 8.4 & 17.9 & & 67.4 & 67.8 \\
\hline
\end{tabular}



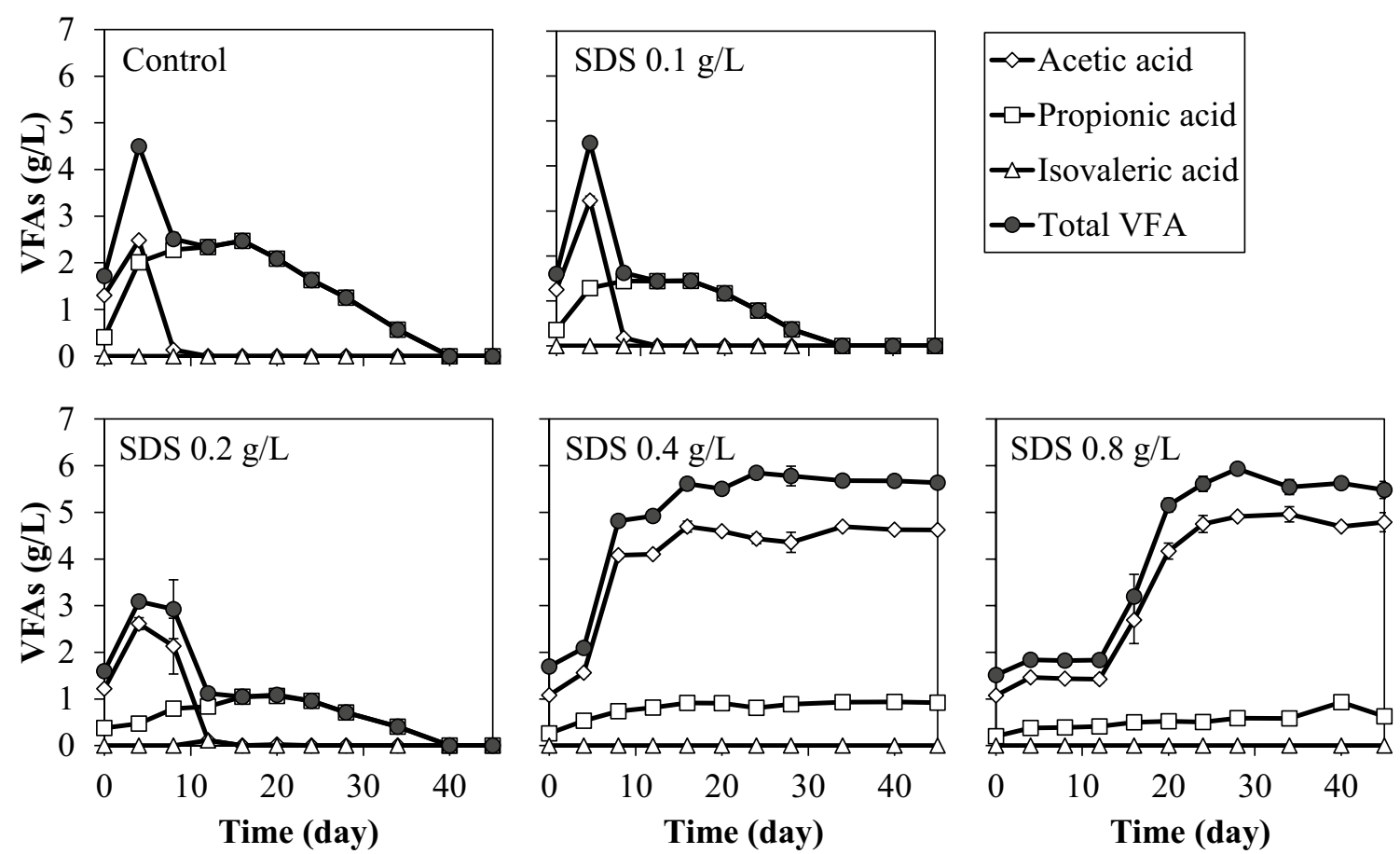

Fig. 4 Time course of VFA concentration during the methane fermentation of waste paper pretreated in rumen fluid at various SDS concentrations (control, $0.1,0.2,0.4$, or $0.8 \mathrm{~g} / \mathrm{L}$ )

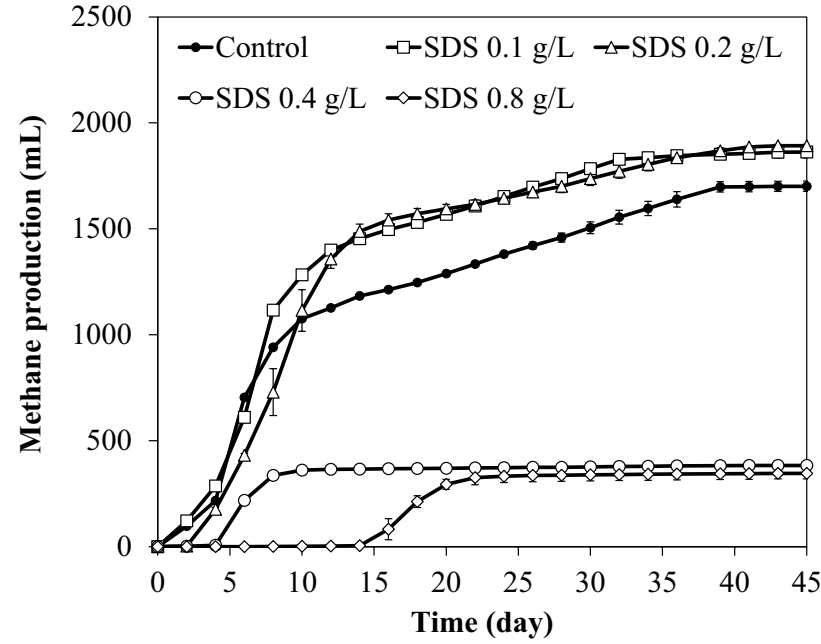

Fig. 5 Effect of SDS addition on cumulative methane production from the pretreated waste paper during methane fermentation

concentrations of 0.4 and $0.8 \mathrm{~g} / \mathrm{L}$ decreased production by 77.5 and $79.7 \%$, respectively.

Figure 6 presents the methane and carbon dioxide contents of the biogas. The methane contents from waste paper pretreated with rumen fluid mixed with 0.0, 0.1, and $0.2 \mathrm{~g} / \mathrm{L}$ SDS ranged from 60.2 to $83.8 \%$ at day 7 to day 32. These rates were much higher than those at SDS concentrations of 0.4 and $0.8 \mathrm{~g} / \mathrm{L}$ (Fig. 6a). By contrast, the carbon dioxide contents of all treatments ranged from 0.7 to $55.7 \%$ (Fig. 6b), and none of the SDS pretreatments changed the maximum carbon dioxide content. The carbon dioxide contents increased for the first four days, then decreased quickly in SDS concentrations of 0.0, 0.1, $0.2 \mathrm{~g} / \mathrm{L}$. Meanwhile, pretreatment with SDS concentrations of 0.4 and $0.8 \mathrm{~g} / \mathrm{L}$ showed the maximum carbon dioxide contents on day 8 and day 20, respectively. In addition, the carbon dioxide contents decreased slowly in SDS concentrations of 0.4 and $0.8 \mathrm{~g} / \mathrm{L}$.

Table 3 presents the methane production $(\mathrm{mL})$, methane yield (\%), and technical digestion time $\left(T_{80}\right)$. The methane yields after pretreatment with SDS concentrations of 0.1 and $0.2 \mathrm{~g} / \mathrm{L}$ were 9.0 and $10.0 \%$ higher than that of the control. However, the methane yields after pretreatment with SDS concentrations of 0.4 and $0.8 \mathrm{~g} / \mathrm{L}$ were 78.0 and $80.5 \%$ lower than that of the control. The $\mathrm{T}_{80}$ is defined as the digestion time required to reach $80 \%$ of the total methane production [10], which indicates the economic benefit of improving the treatment capacity of a biogas plant. The $\mathrm{T}_{80}$ values for the batches pretreated with SDS concentrations of 0.1 and $0.2 \mathrm{~g} / \mathrm{L}$ were 31.9 and $34.0 \%$ shorter than that of the control, respectively. 

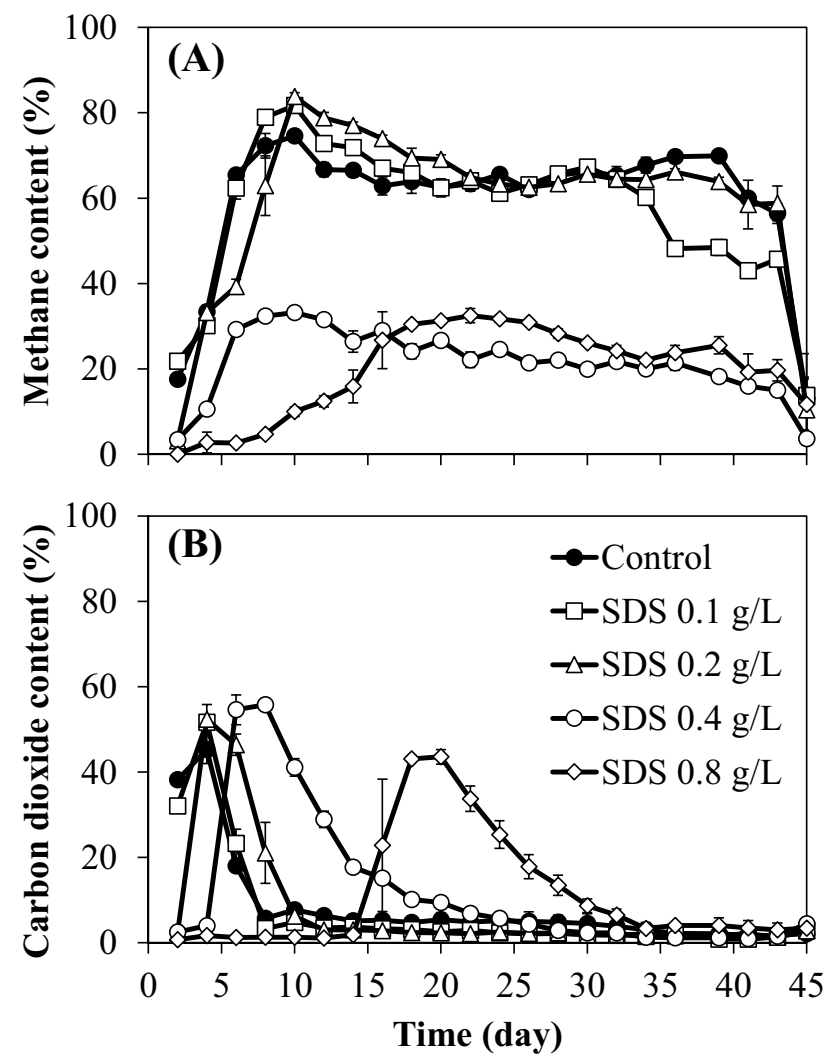

Fig. 6 Time course of a methane and $\mathbf{b}$ carbon dioxide concentration during the methane fermentation of waste paper pretreated in rumen fluid at various SDS concentrations (control, $0.1,0.2,0.4$, or $0.8 \mathrm{~g} / \mathrm{L}$ )

Table 3 Effect of SDS addition on total methane production, methane yield, and technical digestion time (T80) of waste paper

\begin{tabular}{lllll}
\hline & \multicolumn{2}{l}{ Methane production $(\mathrm{mL})$} & $\begin{array}{l}\text { Methane } \\
\text { yield (\%) }\end{array}$ & T80 (days) \\
\cline { 2 - 4 } & \multicolumn{5}{c}{ Pretreatment } & $\begin{array}{l}\text { Methane } \\
\text { fermenta- } \\
\text { tion }\end{array}$ & \\
\hline Control & 9.5 & 1700.7 & 59.3 & 23.5 \\
SDS 0.1 g/L & 9.7 & 1862.3 & 64.7 & 16.0 \\
SDS 0.2 g/L & 5.4 & 1892.3 & 65.3 & 15.5 \\
SDS 0.4 g/L & 0.4 & 383.2 & 13.1 & 8.0 \\
SDS 0.8 g/L & 0.0 & 346.1 & 11.6 & 21.0 \\
\hline
\end{tabular}

\section{Discussion}

\section{Effect of SDS addition on pretreatment with rumen fluid}

Adding SDS during pretreatment increased rumen ciliate mortality (Fig. 1). This finding is consistent with that of a previous study of the effects of defaunation on the fermentation characteristics of starchy feed sources, which revealed that rumen ciliates were eliminated by adding SDS after $1 \mathrm{~h}$ of incubation [18]. Surfactants react with cholesterol in eukaryotic cell membranes [19], which alter membrane fluidity and permeability via increased unsaturation of lipids [20,21]. Thus, SDS lyses the cell membrane of rumen ciliates [22], thereby increasing mortality. Elimination of rumen ciliates by SDS can result in an increase in bacterial populations due to a decrease in bacteria engulfed by rumen ciliates and supplementation of nutrients from lysed protozoan cells supporting bacterial reproduction [23]. In addition, SDS can alter the ultrastructure of waste paper, increasing its vulnerability to enzymatic attack [24]. In this study, we speculated that increased vulnerability of waste paper to microbial attack and lysis of ciliates would result in an increase in dissolved COD during waste paper pretreatment. Meanwhile, SDS addition at $0.8 \mathrm{~g} / \mathrm{L}$ markedly decreased the VFA content (Fig. 2). High concentration of SDS likely affected not only ciliates but also VFA-producing bacteria. In this study, considerable differences in the degradability of TS and VS with treatment were not observed (Table 2), although the dissolved COD increased with increased SDS concentrations (Fig. 2a). It is estimated that the increase of dissolved COD was due to the solubilization of waste paper, the lysis of rumen ciliates, and/or the dispersion of insoluble compounds. Further investigations will be necessary to reveal the biological and the physical effects of SDS on the lignocellulose digestion by ruminal microorganisms in greater detail.

\section{Gas production during pretreatment with rumen fluid}

During pretreatment, adding 0.2, 0.4, and $0.8 \mathrm{~g} / \mathrm{L}$ SDS remarkably decreased methane production (Fig. 3a), whereas 0.1 and $0.2 \mathrm{~g} / \mathrm{L}$ SDS increased carbon dioxide production (Fig. 3b). Eliminating protozoa from rumen fluid using SDS decreased methane production and increased carbon dioxide production from forage sources [25]. In rumen, protozoa have symbiotic relationships with methanogens. Protozoa generate large amounts of hydrogen, which must be removed to facilitate fermentation of ingested feed [26]. Methanogens convert carbon dioxide and the hydrogen generated by protozoa into methane. Thus, our results indicate that SDS addition eliminated not only ciliates but also symbiotic methanogens, resulting in a decrease in methane gas production by methanogens and an increase in carbon dioxide production. 


\section{Effect of SDS on methane fermentation of waste paper}

Pretreatment with SDS at concentrations of 0.1 and $0.2 \mathrm{~g} / \mathrm{L}$ improved the methane yield from waste paper and shortened the $T_{80}$ after fermentation (Table 3 ). High methane yields produced in shorter times could potentially be realized, which would confer economic benefits and improve the production efficiency and/or the treatment capacity of biogas facilities [27]. In this study, the improvement in methane production was possibly the results of eliminating rumen ciliates (Fig. 1), increasing of dissolved COD during pretreatment (Fig. 2a), and decreasing propionic acid concentration during methane fermentation (Fig. 4). As described above, the elimination of rumen ciliates by SDS resulted in an increase of dissolved organic compounds from lysed protozoan cells and an increase in bacterial populations [23]. It was estimated that dissolved organic compounds could be quickly converted into methane and that an increase in bacteria caused the degradation of waste paper during pretreatment and methane fermentation. Propionic acid degradation is the rate-limiting step in methane fermentation, compared with acetic acid degradation. Thus, in this study, SDS at 0.1 and $0.2 \mathrm{~g} / \mathrm{L}$ may have enhanced the fibrolytic activity of microorganisms, resulting in an increase of methane production from waste paper. In addition, SDS at 0.1 and $0.2 \mathrm{~g} / \mathrm{L}$ may have increased the dissolved organic compounds and decreased the propionic acid concentration, resulting in a shortened time for methane production.

SDS addition at 0.4 and $0.8 \mathrm{~g} / \mathrm{L}$ resulted in the accumulation of acetic acid and propionic acid (Fig. 4), which decreased the $\mathrm{pH}$ of the system below 6.0. In addition, SDS addition at 0.4 and $0.8 \mathrm{~g} / \mathrm{L}$ decreased the methane contents (Fig. 6a) and the efficiency of methane production from waste paper during methane fermentation (Table 3 ). These results indicated that the addition of high SDS concentrations during pretreatment inhibited methanogens rather than VFA-producing microorganisms. In previous studies, propionic acid concentrations of $0.9 \mathrm{~g} / \mathrm{L}$ resulted in significant inhibition of methanogens [28], and methane production by methanogens was markedly inhibited when the $\mathrm{pH}$ was lower than 6.1 [29]. Thus, we speculated that SDS addition improved VFA production, but also inhibited their consumption by methanogens, causing an accumulation of VFAs (i.e., acetic acid and propionic acid) and a decrease in $\mathrm{pH}$ below 6.0. As a result, the accumulated VFAs and low $\mathrm{pH}$ markedly inhibited methane production from waste paper.

\section{Conclusions}

We assessed whether SDS amendment with rumen fluid could improve the efficiency of waste paper pretreatment and subsequent methane fermentation. During the pretreatment with rumen fluid, SDS addition at all tested concentrations decreased ciliate viability. Moreover, SDS addition increased the dissolved COD content, although SDS addition did not increase the VFA concentration during pretreatment. During methane fermentation, pretreatment with SDS concentrations of 0.1 and $0.2 \mathrm{~g} / \mathrm{L}$ resulted in decreased propionic acid concentrations, shortened the waste paper digestion time, and improved methane yield. In contrast, pretreatment with SDS concentrations of 0.4 and $0.8 \mathrm{~g} / \mathrm{L}$ resulted in VFA accumulation, ultimately causing the inhibition of methane production during methane fermentation. Thus, it can be concluded that pretreatment using rumen fluid with SDS addition at concentrations of 0.1 or $0.2 \mathrm{~g} / \mathrm{L}$ can improve waste paper pretreatment and ultimately enhance methane production. This is the first study to reveal that feed additives can be applied to pretreatment with rumen fluid for the enhancement of methane production from lignocellulosic biomass. Further investigations using various feed additives may offer further improvements to the methane fermentation process.

Acknowledgements This study was supported by a Japan Society for the Promotion of Science KAKENHI Grant [JP17H01512 and JP19J12745]; the Miyagi Prefectural Government Recycling Promotion Division; and the Miyagi Organization for Industry Promotion. We wish to thank Mr. Masaki Tannai and Ms. Rie Sato of the Field Science Center, Graduate School of Agricultural Science, Tohoku University for their technical support during the collection of the rumen fluid.

\section{Compliance with ethical standards}

Conflict of interest The author(s) declears that they have no conflict of interest.

Open Access This article is licensed under a Creative Commons Attribution 4.0 International License, which permits use, sharing, adaptation, distribution and reproduction in any medium or format, as long as you give appropriate credit to the original author(s) and the source, provide a link to the Creative Commons licence, and indicate if changes were made. The images or other third party material in this article are included in the article's Creative Commons licence, unless indicated otherwise in a credit line to the material. If material is not included in the article's Creative Commons licence and your intended use is not permitted by statutory regulation or exceeds the permitted use, you will need to obtain permission directly from the copyright holder. To view a copy of this licence, visit http://creativecommons.org/licenses/by/4.0/.

\section{References}

1. Sawatdeenarunat C, Surendra KC, Takara D et al (2015) Anaerobic digestion of lignocellulosic biomass: challenges and opportunities. Bioresour Technol 178:178-186. https://doi.org/10.1016/j. biortech.2014.09.103

2. Torres ML, Lloréns MCE (2008) Effect of alkaline pretreatment on anaerobic digestion of solid wastes. Waste Manag 28:2229 2234. https://doi.org/10.1016/j.wasman.2007.10.006 
3. Saha M, Eskicioglu C, Marin J (2011) Microwave, ultrasonic and chemo-mechanical pretreatments for enhancing methane potential of pulp mill wastewater treatment sludge. Bioresour Technol 102:7815-7826. https://doi.org/10.1016/j.biortech.2011.06.053

4. Wood N, Tran H, Master E (2009) Pretreatment of pulp mill secondary sludge for high-rate anaerobic conversion to biogas. Bioresour Technol 100:5729-5735. https://doi.org/10.1016/j.biort ech.2009.06.062

5. Kamra DN (2005) Rumen microbial ecosystem. Curr Sci $89: 124-135$

6. Güllert S, Fischer MA, Turaev D et al (2016) Deep metagenome and metatranscriptome analyses of microbial communities affiliated with an industrial biogas fermenter, a cow rumen, and elephant feces reveal major differences in carbohydrate hydrolysis strategies. Biotechnol Biofuels 9:1-20. https://doi.org/10.1186/ s13068-016-0534-x

7. Wongwilaiwalin S, Laothanachareon T, Mhuantong W et al (2013) Comparative metagenomic analysis of microcosm structures and lignocellulolytic enzyme systems of symbiotic biomass-degrading consortia. Appl Microbiol Biotechnol 97:8941-8954. https://doi. org/10.1007/s00253-013-4699-y

8. Baba Y, Tada C, Fukuda Y, Nakai Y (2013) Improvement of methane production from waste paper by pretreatment with rumen fluid. Bioresour Technol 128:94-99. https://doi.org/10.1016/j. biortech.2012.09.077

9. Baba Y, Matsuki Y, Mori Y et al (2017) Pretreatment of lignocellulosic biomass by cattle rumen fluid for methane production: bacterial flora and enzyme activity analysis. J Biosci Bioeng 123:489-496. https://doi.org/10.1016/j.jbiosc.2016.11.008

10. Zhang $\mathrm{H}$, Zhang $\mathrm{P}, \mathrm{Ye} \mathrm{J}$ et al (2016) Improvement of methane production from rice straw with rumen fluid pretreatment: a feasibility study. Int Biodeterior Biodegrad 113:9-16. https://doi. org/10.1016/j.ibiod.2016.03.022

11. Takizawa S, Baba Y, Tada C et al (2018) Pretreatment with rumen fluid improves methane production in the anaerobic digestion of paper sludge. Waste Manag 78:379-384. https://doi.org/10.1016/j. wasman.2018.05.046

12. Patra AK, Stiverson J, Yu Z (2012) Effects of quillaja and yucca saponins on communities and select populations of rumen bacteria and archaea, and fermentation in vitro. J Appl Microbiol 113:1329-1340. https://doi.org/10.1111/j.1365-2672.2012.05440 . $\mathrm{X}$

13. Anantasook N, Wanapat M, Cherdthong A, Gunun P (2015) Effect of tannins and saponins in Samanea saman on rumen environment, milk yield and milk composition in lactating dairy cows. J Anim Physiol Anim Nutr 99:335-344. https://doi.org/10.1111/jpn.12198

14. Cong ZH, Tang SX, Tan ZL et al (2009) Effects of different nonionic surfactants on in vitro fermentation characteristics of cereal straws. J Anim Sci 87:1085-1096. https://doi.org/10.2527/ jas.2008-1316

15. Santra A, Karim SA (2002) Influence of ciliate protozoa on biochemical changes and hydrolytic enzyme profile in the rumen ecosystem. J Appl Microbiol 92:801-811. https://doi.org/10.1007/ s10803-016-2703-y

16. APHA (2012) Standard methods for the examination of water and wastewater, 21st edn. American Public Health Association Washington, DC, USA
17. Ogimoto K, Imai S (1981) Atlas of rumen microbiology. Japan Scientific Societies Press, Tokyo

18. Qin WZ, Li CY, Kim JK et al (2012) Effects of defaunation on fermentation characteristics and methane production by rumen microbes in vitro when incubated with starchy feed sources. Asian-Australasian J Anim Sci 25:1381-1388. https://doi. org/10.5713/ajas.2012.12240

19. Wina E, Muetzel S, Becker K (2005) The impact of saponins or saponin-containing plant materials on ruminant production-a review. J Agric Food Chem 53:8093-8105. https://doi. org/10.1021/jf048053d

20. Yazdi MT, Woodward JR, Radford A (1990) The cellulase complex of Neurospora crassa: activity, stability and release. J Gen Microbiol 136:1313-1319. https://doi.org/10.1099/00221 287-136-7-1313

21. Reese ET, Maguire A (1969) Surfactants as stimulants of enzyme production by microoganisms. Appl Microbiol 17:242-245

22. Klita PT, Mathison GW, Fenton TW, Hardin RT (1996) Effects of alfalfa root saponins on digestive function in sheep. J Anim Sci 74:1144-1156. https://doi.org/10.2527/1996.7451144x

23. Hristov AN, Ivan M, Rode LM, McAllister TA (2001) Fermentation characteristics and ruminal ciliate protozoal populations in cattle fed medium- or high-concentrate barley-based diets. J Anim Sci 79:515-524. https://doi.org/10.2527/2001.792515x

24. Eriksson T, Börjesson J, Tjerneld F (2002) Mechanism of surfactant effect in enzymatic hydrolysis of lignocellulose. Enzyme Microb Technol 31:353-364. https://doi.org/10.1016/S0141 $-0229(02) 00134-5$

25. Qin W, Choi S, Lee S et al (2013) Effect of defaunation on in vitro fermentation characteristics and methane emission when incubated with forages. J Korean Soc Grassl Forage Sci 33:197-205

26. Newbold CJ, De la Fuente G, Belanche A et al (2015) The role of ciliate protozoa in the rumen. Front Microbiol 6:1-14. https:// doi.org/10.3389/fmicb.2015.01313

27. Zhong W, Zhang Z, Luo Y et al (2011) Effect of biological pretreatments in enhancing corn straw biogas production. Bioresour Technol 102:11177-11182. https://doi.org/10.1016/j.biort ech.2011.09.077

28. Wang Y, Zhang Y, Wang J, Meng L (2009) Effects of volatile fatty acid concentrations on methane yield and methanogenic bacteria. Biomass Bioenerg 33:848-853. https://doi.org/10.1016/j.biomb ioe.2009.01.007

29. Jiunn-Jyi L, Yu-You L, Noike T (1997) Influences of pH and moisture content on the methane production in high-solids sludge digestion. Water Res 31:1518-1524. https://doi.org/10.1016/ S0043-1354(96)00413-7

Publisher's Note Springer Nature remains neutral with regard to jurisdictional claims in published maps and institutional affiliations. 